\title{
Evidence for Priming and Inhibitory Effects of Glucose on Insulin Secretion from Isolated Islets of Langerhans
}

\author{
J. P. Ashby and D. Shirling \\ Metabolic Unit, University Department of Medicine, Western General Hospital, Edinburgh, Scotland
}

Summary. Biphasic insulin secretion from perifused rat islets of Langerhans was affected in three ways by the islet glucose environment prior to stimulation: (i) The secretory response to glucose was diminished if the basal concentration of glucose in the medium was reduced from 5.5 to $2.7 \mathrm{mmol} / 1$ for $2 \mathrm{~h}$ prior to stimulation. First phase secretion was affected more than the second. (ii) Secretion was potentiated if islets had been previously exposed to a stimulatory concentration of glucose of $22.2 \mathrm{mmol} / \mathrm{l}$. Again first phase secretion was particularly affected and there was a positive correlation between the magnitude of the secretory response and the duration of the initial stimulus. (iii) In contrast, both phases of secretion were proportionately reduced if islets had been previously exposed to stimulatory concentrations of glucose of $8.3 \mathrm{mmol} / 1$.

Key words: Biphasic insulin secretion, perifused islets of Langerhans, regulation by glucose, potentiation.

Sustained stimulation by glucose leads to a biphasic pattern of insulin secretion from the pancreatic B cell in vivo $[1,2]$ and in vitro $[3,4]$. Phase 1 consists of a rapid surge of insulin secretion which reaches a peak value within a few minutes and then declines. In man [1] and the rat [4] this is followed by a slower progressive rise in the secretory rate known as Phase 2.

Because a similar relationship between insulin secretion and glucose concentration has been observed for the two phases of secretion [5], it has been suggested that they are both a consequence of a common intracellular event induced by glucose. However, the finding that Phase I is disproportionately reduced during starvation [6] together with claims that a reduction in this acute insulin response is one of the earliest detectable abnormalities occurring in diabetes mellitus $[7,8]$ suggests that Phases I and II may be controlled separately to some extent.

Although the magnitude of both secretory phases is dependent on the prevailing glucose concentration, it also appears to be influenced by preceding hyperglycaemic stimuli. In vivo studies in man [9] and experiments with the perfused rat pancreas [10] have shown that a sustained period of glucose stimulation will potentiate both phases of secretion in response to a subsequent glucose load. In contrast, when two transient glucose challenges are given at short intervals in man the insulin response to the second stimulus is greatly diminished [11]. These apparently conflicting observations have not been adequately explained, and the conditions under which they can be reproduced in vitro have not been fully characterized.

The aims of the present investigation were to examine factors regulating the Phase I and II secretory responses to glucose, and to define the conditions under which glucose may exert its paradoxical stimulatory and inhibitory effects on the response to a subsequent glucose load. The experiments were carried out with perifused rat islets of Langerhans.

\section{Material and Methods}

\section{Isolation of Islets of Langerhans}

Male Wistar albino rats weighing approximately $200 \mathrm{~g}$ were fed ad libitum on a standard laboratory diet containing $48 \%$ carbohydrate, $21.3 \%$ protein and $3.4 \%$ fat. Islets were isolated by collagenase digestion [12]. The medium used for isolation of islets and all subsequent experiments was a bicarbonate buffered salt solution supplemented with sodium salts of glutamic, lactic and fumaric acids at a concentration of $5 \mathrm{mmol} / \mathrm{l}$ [13]. The gas phase was $\mathrm{O}_{2}: \mathrm{CO}_{2}(95: 5)$. The glucose concentration of the medium used for islet isolation was either 2.7 or $5.5 \mathrm{mmol} / \mathrm{l}$. 


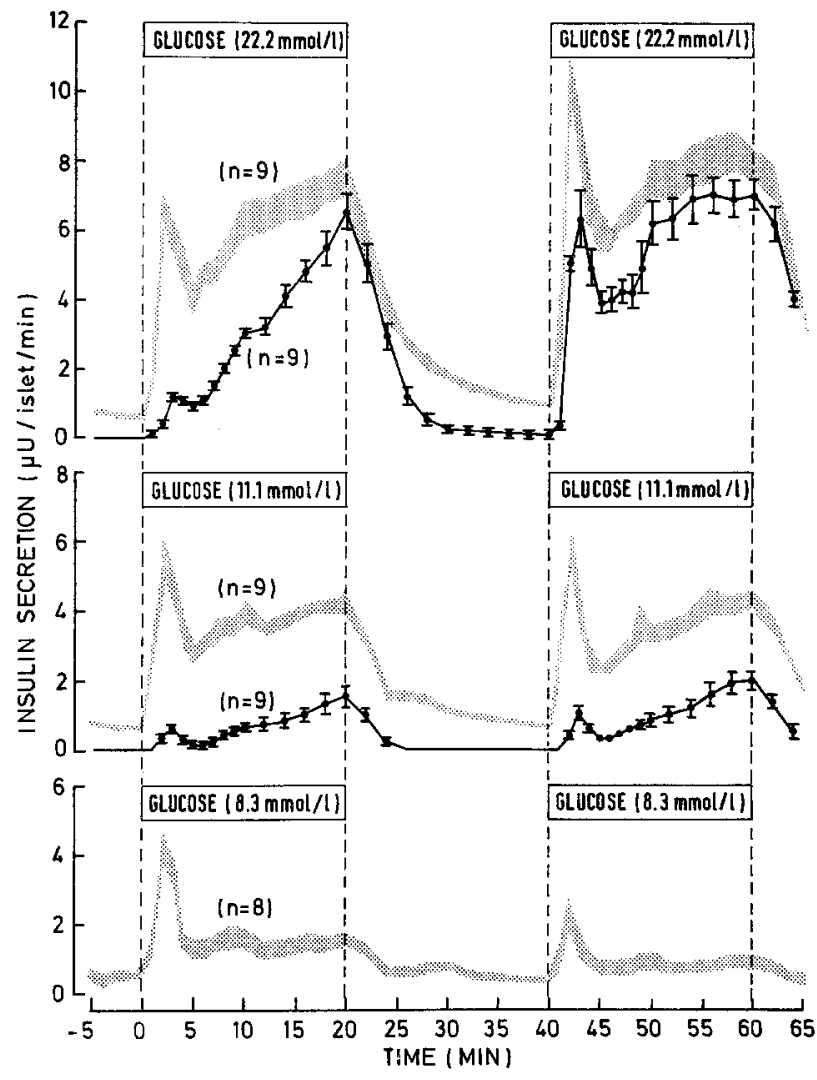

Fig. 1. Insulin secretion in response to two consecutive stimulations with glucose. Solid lines denote the mean secretory response $\pm \mathrm{SEM}$ for islets equilibrated in $2.7 \mathrm{mmol} / 1$ glucose. Shaded portions denote insulin secretion by islets equilibrated in $5.5 \mathrm{mmol} / 1$ glucose and represent the area enclosed by the mean \pm SEM. The results were obtained in three separate experiments for each basal glucose concentration. In each experiment islets were selected from a pool obtained from three separate collagenase digestions

In a typical experiment 3 separate collagenase digestions were carried out simultaneously. Each digest contained pancreatic tissue obtained from 2-3 rats. Islets obtained from each of the three digests were placed in a common pool before selection for perfusion. This procedure was carried out on 3 separate occasions in the first study (Fig. 1) and on two separate occasions in subsequent studies (Figs. 2 and 3). Some variation was observed in the total amount of insulin secreted by islets prepared on different occasions. For example, in the first study (Fig. 1) variance ratios calculated using the total insulin secreted during the first stimulation period with $22.2 \mathrm{mmol} / \mathrm{I}$ glucose were $14.0(\mathrm{p}<0.01)$ and 5.2 $(\mathrm{p}<0.05)$ in the presence of 2.7 and $5.2 \mathrm{mmol} / 1$ basal glucose. Day-to-day variation was insignificant in the second (Fig. 2), and third (Fig. 3) studies. In these experiments the variance ratios calculated using the total insulin secreted in response to the initial stimulus of $16.6 \mathrm{mmol} / \mathrm{l}$ glucose were 5.8 and 1.8 respectively.

\section{Perifusion of Islets}

The perifusion chambers consisted of a $3.5 \mathrm{~cm}$ length of a yellow Eppendorf pipette tip (range $5-100 \mu 1$ ) the narrow end of which was occluded with a small piece of plastic foam in order to retain the islets. The medium was pumped over the islets at a rate of $1 \mathrm{ml} / \mathrm{min}$ by a multi-channel Desaga PLG peristaltic pump which produced a practically pulseless flow and hence caused minimal physical agitation of the islets. A three way tap permitted the selection of control or experimental medium and was placed between the pump and the media reservoirs. Silicone tubing with an internal diameter of $0.5 \mathrm{~mm}$ connected the perifusion chamber with both the three way tap and the collection manifold, the total dead space being approximately $0.5 \mathrm{ml}$. The perifusion chambers, media reservoirs and as much of the interconnecting tubing as possible were immersed in thermostatically controlled water baths at $37^{\circ} \mathrm{C}$.

Up to 12 groups of 30 islets selected from the common pool were perifused simultaneously. After loading, all islets were perifused for a minimum of $40 \mathrm{~min}$ with medium containing a basal glucose concentration of either 5.5 or $2.7 \mathrm{mmol} / 1$. The average time interval between the removal of the pancreas and the administration of the first glucose stimulus was $2 \mathrm{~h}$.

Two main types of experiment were carried out. Islets were either subjected to two consecutive sustained stimulations with glucose applied $20 \mathrm{~min}$ apart or were stimulated repetitively with transient pulses of glucose which were of 4 min duration and administered $6 \mathrm{~min}$ apart. The stimulatory concentration of glucose to which the islets were exposed was not changed during the course of an experiment. On switching from basal to stimulatory levels of glucose the concentration of glucose in the perifusate reached a maximum within 45 seconds. The level declined equally rapidly on switching back to medium containing basal glucose.

Samples of perifusate were collected over 2 min periods when islets were perifused with a low glucose concentration (2.7 or $5.5 \mathrm{mmol} / \mathrm{l}$ ). When the glucose levels were increased above basal for a sustained period, samples were normally collected at 1-min intervals for 10 -min after the change and at 2-min intervals thereafter. When islets were stimulated repetitively with glucose samples were collected at 1-min intervals throughout the experiment. The constancy of flow rate in each channel was checked during the course of each experiment and any minor variation in flow rate between channels accounted for when insulin secretory rates were calculated.

\section{Analytical Methods}

The concentration of glucose in all media was checked using a glucose oxidase method. Insulin was assayed by radioimmunoassay [13] using purified rat insulin as standard (Novo Research Institute, Copenhagen, Denmark). All results are presented as means \pm SEM and were analysed using the Student's t-test for paired and non-paired data. Day-to-day variation in the total amount of insulin secreted by different batches of islets was assessed by calculation of the variance ratio.

\section{Results}

\section{A. Effect of the Basal Glucose Concentration on Glucose-induced Insulin Secretion}

Secretory profiles observed when islets were subjected to two sustained periods of stimulation with either $22.2,11.1$ or $8.3 \mathrm{mmol} / 1$ glucose are shown in Figure 1. When islets were equilibrated in medium containing a basal glucose concentration of $5.5 \mathrm{mmol} / \mathrm{l}$ a vigorous biphasic secretory response occurred during the initial stimulation period. In the 
presence of $22.2 \mathrm{mmol} / 1$ glucose the total insulin secretion was $107.9 \pm 8.4 \mu \mathrm{U} /$ islet $(\mathrm{n}=9)$ with Phase I accounting for $19.4 \pm 1.0 \%$ of the total secretion. In contrast, when islets were equilibrated in $2.7 \mathrm{mmol} / 1$ glucose the total insulin released in response to initial stimulation with $22.2 \mathrm{mmol} / 1 \mathrm{glu}-$ cose $(70.2 \pm 6.6 \mu \mathrm{U} /$ islet, $\mathrm{n}=9)$ was significantly less $(p<0.01)$. Although both phases of secretion were impaired under these conditions, Phase I was reduced to the greatest extent since it now accounted for a significantly smaller proportion of the total secretion $(5.7 \pm 0.2 \%, \mathrm{n}=9, \mathrm{p}<0.001)$. Insulin secretion from islets equilibrated in $2.7 \mathrm{mmol} / 1$ was similarly reduced in response to stimulation with $11.1 \mathrm{mmol} / 1$ glucose and was undetectable in the presence of $8.3 \mathrm{mmol} / \mathrm{l}$ glucose.

When islets equilibrated in $5.5 \mathrm{mmol} / 1$ glucose were stimulated for a second time, the response to $11.1 \mathrm{mmol} / 1$ glucose was comparable in magnitude to that observed during the initial stimulation period. However, when the stimulating concentration of glucose was $8.3 \mathrm{mmol} / \mathrm{l}$, insulin secretion was significantly reduced in response to a second stimulus. (Stimulus 1, $23.2 \pm 2.3 \mu \mathrm{U}$ /islet; stimulus 2, $11.9 \pm$ $1.9 \mu \mathrm{U} /$ islet; $\mathrm{p}<0.001, \mathrm{n}=8$ ). In contrast, the total secretion of insulin observed during the second period of stimulation with $22.2 \mathrm{mmol} / 1$ glucose (125.6 $\pm 7.7 \mu \mathrm{U} /$ islet, $\mathbf{n}=9$ ), was significantly greater than that observed initially. $(\mathrm{p}<0.01)$. Phase I now accounted for a significantly greater proportion $(23.8 \pm 1.2 \% ; \mathrm{p}<0.001)$ of the total insulin secreted during the $20 \mathrm{~min}$ stimulation period.

When islets equilibrated in $2.7 \mathrm{mmol} / 1$ glucose were stimulated for a second time with $11.1 \mathrm{mmol} / 1$ glucose a small but statistically significant increase in the total insulin secretion was observed (Stimulus 1, $14.8 \pm 2.8 \mu \mathrm{U} /$ islet; stimulus $2,21.4 \pm 4 \mu \mathrm{U} /$ islet; $\mathrm{p}<0.01, \mathrm{n}=9$ ). However, the total secretion of insulin observed during the second period of stimulation with $22.2 \mathrm{mmol} / 1$ glucose $(122.2 \pm 7 \mu \mathrm{U} /$ islet, $\mathrm{n}=9$ ) was markedly greater than that observed initially $(\mathrm{p}<0.001)$. Again, Phase I was particularly affected so that its contribution to the total insulin secreted $(17.2 \pm 0.6 \%)$ was increased significantly $(\mathrm{p}<0.001)$.

\section{B. Time Course of Potentiation}

The relationship between the increase in Phase I secretion and the duration of the initial stimulus was investigated. Islets were equilibrated in $2.7 \mathrm{mmol} / 1$ glucose and then subjected to two successive stimuli ( $16.6 \mathrm{mmol} / 1$ glucose) with a $20 \mathrm{~min}$ interval between them. The duration of the initial stimulation period varied between 5 and $20 \mathrm{~min}$ but was always suffi-

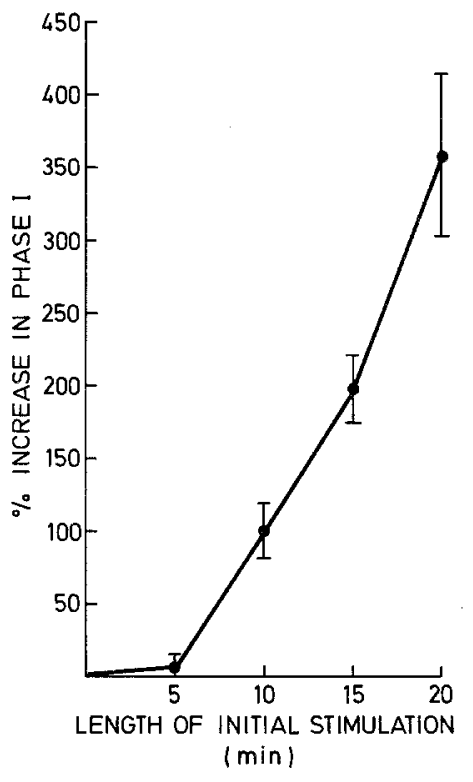

Fig. 2. Relationship between the duration of an initial stimulation period with $16.6 \mathrm{mmol} / \mathrm{l}$ glucose and the percentage increase in Phase I secretion observed during a second stimulation applied 20 min later. Results represent the mean $\pm \operatorname{SEM}(n=6$ throughout) and were obtained in two separate experiments. In each experiment islets were selected from a pool obtained from 3 separate collagenase digestions. Prior to stimulation islets were equilibrated for $2 \mathrm{~h}$ in $2.7 \mathrm{mmol} / 1$ glucose

cient to produce a complete Phase I response. The second stimulus was maintained for $20 \mathrm{~min}$. Figure 2 demonstrates that the magnitude of the Phase I response during the second period of stimulation was increased with the duration of the initial stimulus provided it exceeded $5 \mathrm{~min}$.

In a further experiment islets equilibrated in $5.5 \mathrm{mmol} / 1$ glucose were subjected to repetitive stimuli which were applied six minutes apart. The concentration of glucose was identical during each stimulation and was maintained for a period of $4 \mathrm{~min}$ on each occasion. The secretory response to 16.6 , 11.1 or $8.3 \mathrm{mmol} / 1$ glucose was studied in this way. Figure $3 \mathrm{~A}$ demonstrates that after an initial delay the secretory response of islets repetitively stimulated with $16.6 \mathrm{mmol} / \mathrm{l}$ glucose steadily increased. Thus when the period between stimulations is reduced even short periods of glucose stimulation may potentiate secretory response to oncoming stimuli. When the stimulating concentration of glucose was $11.1 \mathrm{mmol} / 1$, comparable rates of insulin secretion were observed throughout the experiment (Fig. 3B). However when the stimulating concentration of glucose was reduced to $8.3 \mathrm{mmol} / 1$ the secretory response steadily declined (Fig. 3C). 


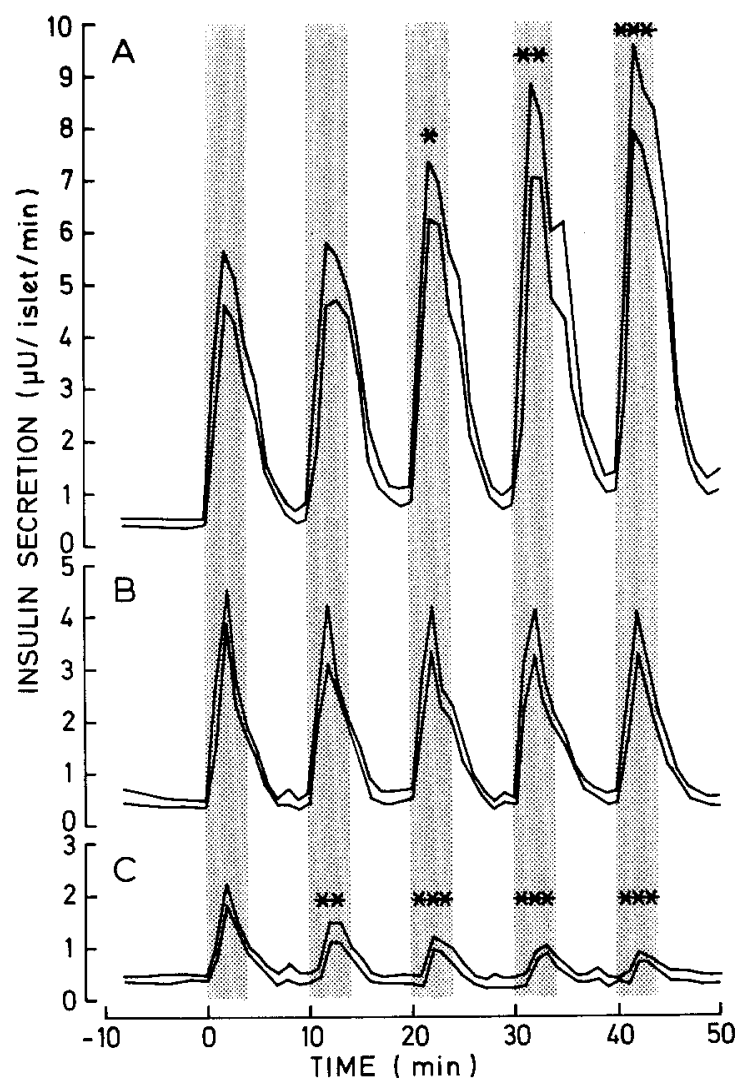

Fig. 3. Islet secretory response to repetitive stimulation with 16.6 (A), 11.1 (B) and 8.3 (C) mmol/l glucose. Shaded bars denote the periods of glucose stimulation and the profiles represent the mean secretion \pm SEM $(n=7)$ observed in two separate experiments. In each experiment islets were selected from a pool obtained from three separate collagenase digestions. Islets were equilibrated for $2 \mathrm{~h}$ in $5.5 \mathrm{mmol} / 1$ glucose prior to stimulation. Significance of difference from the response shown during the initial stimulation period: ${ }^{*} \mathrm{p}<0.02 ;{ }^{* * \mathrm{p}}<0.01 ;{ }^{* * *} \mathrm{p}<0.001$

\section{Discussion}

These experiments confirm that the secretion of insulin is profoundly influenced by the concentration of glucose bathing the $\beta$ cell prior to stimulation $[9,10$, $11,14]$.

Firstly, the secretory response to glucose is markedly reduced following prolonged exposure to a low basal concentration of glucose. Although both phases of insulin secretion are affected the Phase I response is impaired to a greater extent. Since these findings are similar to those made using islets isolated from fasted animals [6] they add further support to the suggestion that the effect of starvation on insulin secretion is due simply to a prolonged depression of the blood glucose concentration [15]. Experiments performed with isolated islets of Langerhans incubated in vitro indicate that this may lead to a decrease in islet ATP concentration [16]. A similar hypothesis could also explain the observations that insulin secretion in response to a mixed meal is impaired following a short period of insulin-induced hypoglycaemia in man [17].

Secondly, in accordance with in vitro [10] and in vivo [9] studies, it has been demonstrated that a brief exposure to a high stimulatory concentration of glucose may potentiate the secretory response to a subsequent glucose load.

The experiments with islets equilibrated in $5.5 \mathrm{mmol} / \mathrm{l}$ glucose indicate that while the insulin response starts at glucose levels below $8.3 \mathrm{mmol} / 1$, potentiation of insulin secretion in response to a second stimulus is unlikely to occur unless the glucose concentration during the initial stimulation period is somewhat greater than $11.1 \mathrm{mmol} / 1$. Thus the induction of potentiation by glucose may have dose response characteristics which differ from the welldefined relationship between glucose and insulin secretion suggesting that the two processes may be mediated by distinct intracellular mechanisms. Although the magnitude of both phases of secretion was increased by previous exposure to a high concentration of glucose the results demonstrate that Phase I was enhanced to the greatest extent. This could be due to a transfer of insulin granules from a stable into a peripheral labile pool of insulin which is thought to be mobilised rapidly during Phase I secretion [10]. When the time course of this process was studied it was found that the degree of potentiation was directly proportional to the length of the preincubation period with high glucose.

Finally, conditions were established under which glucose stimulation renders the $\beta$ cell less responsive to a subsequent glucose load. This effect occurred when islets equilibrated in $5.5 \mathrm{mmol} / 1$ glucose were subjected to repeated stimulation with a glucose concentration of $8.3 \mathrm{mmol} / \mathrm{l}$. When two sustained twenty minute stimulation periods were applied both phases of secretion were proportionately reduced during the second period of stimulation (Fig. 1). Similarly, if repetitive transient four minute stimulation periods were used secretion declined progressively (Fig. 3). Further investigation is however necessary to determine whether stimulation with a low concentration of glucose renders the $\beta$ cell less responsive to subsequent stimulations with all levels of glucose including those considerably greater than $11.1 \mathrm{mmol} / \mathrm{l}$. Comparable results have been reported by Cerasi [11] who demonstrated that when two transient glucose challenges were given at short intervals in man the insulin response to the second stimulus was significantly reduced. Since the peak glucose concentration observed during the initial hyperglycaemia stimulus 
in these subjects was approximately $9.4 \mathrm{mmol} / 1$ the results of these human studies and the present in vitro investigations are compatible. However, on the basis of the studies in man it has been suggested that shortly after the onset of stimulation the pancreas enters a refractory phase generated by some factor involved in the activation of insulin release by glucose [5]. The results of the present investigation do not support this hypothesis since they demonstrate that when the degree of $\beta$ cell stimulation is increased by using higher concentrations of glucose the inhibitory response disappears and gives way to the phenomenon of potentiation discussed above.

Acknowledgements. We are grateful to Professor J. A. Strong and Dr. J.D. Baird for encouragement and helpful criticism during these studies, to Carol-Anne McKechnie, Nicola Christie and Susan Taylor for expert technical assistance, and to the Animal Unit of the Western General Hospital for providing the animals used in this study.

\section{References}

1. Cerasi E, Luft R (1967) The plasma insulin response to glucose infusion in healthy subjects and in diabetes mellitus. Acta Endocrinol (Kbh) 55: 278-304

2. Porte D, Pupo A A (1969) Insulin responses to glucose: Evidence for a two pool system in man. J Clin Invest 48: 2309-2319

3. Grodsky G M, Bennett L L, Smith D, Nemechek K (1967) The effect of tolbutamide and glucose on the timed release of insulin from the isolated perfused pancreas. In: Butterfield W J H, Westering W (eds) Tolbutamide after ten years. Excerpta Medica Foundation, Amsterdam, $\mathrm{p} 11-21$

4. Curry D L, Bennett L L, Grodsky G M (1968) Dynamics of insulin secretion by the perfused rat pancreas. Endocrinology 83: 572-584

5. Cerasi E, Fick G, Rudemo M (1974) A mathematical model for the glucose-induced insulin release in man. Eur $\mathrm{J}$ Clin Invest 4: $267-278$

6. Rabinovitch A, Grill V, Renold A E, Cerasi E (1976) Insulin release and cyclic AMP accumulation in response to glucose in pancreatic islets of fed and starved rats. J Clin Invest 58: 1209-1216
7. Colwell J A, Lein A (1967) Diminished insulin response to hyperglycaemia in prediabetes and diabetes. Diabetes 16: $560-565$

8. Serrano-Rios M, Ramos F, Rodriguez-Minon J L, Vivaneo F (1970) Studies in prediabetes. Insulin response to oral glucose, intravenous tolbutamide and rapid intravenous glucose infusion in genetic prediabetes. Diabetologia 6: 392-398

9. Cerasi E (1975) Potentiation of insulin release by glucose in man. I. Quantitative analysis of enhancement of glucoseinduced insulin secretion by pretreatment with glucose in normal subjects. Acta Endocrinol (Kbh) 79: 483-501

10. Grodsky G M (1972) A threshold distribution hypothesis for packet storage of insulin and its mathematical modelling. $\mathrm{J}$ Clin Invest 51: 2047-2059

11. Cerasi E (1975) Feedback inhibition of insulin secretion in subjects with high and low insulin response to glucose. Diabete Metab 1: 73-76

12. Lacy P E, Kostianovsky M (1967) Method for the isolation of intact islets of Langerhans from the rat pancreas. Diabetes 16 : 35-39

13. Ashby J P, Speake R N (1975) Insulin and glucagon secretion from isolated islets of Langerhans: Effects of calcium ionophores. Biochem J 150: 89-96

14. Grill V, Adamson U, Cerasi E (1978) Immediate and timedependent effects of glucose on insulin release from rat pancreatic tissue. Evidence for different mechanisms of action. $\mathbf{J}$ Clin Invest 61: 1034-1043

15. Hedeskov C J, Capito K (1974) Effect of starvation on insulin secretion and glucose metabolism in mouse pancreatic islets. Biochem J 140: 423-433

16. Ashcroft S J H, Weerasinghe CD, Randle P J (1973) Interrelationship of islet metabolism, adenosine triphosphate content and insulin release. Biochem J 132: 223-231

17. Frier BM, Corrall RJM, Ashby JP, Baird JD (in press) Attenuation of the pancreatic beta cell response to a meal following hypoglycaemia in man. Diabetologia

Received: May 30, 1979,

and in final revised form: December 14, 1979

Dr. J. P. Ashby

Metabolic Unit

University Department of Medicine

Western General Hospital

Edinburgh EH4 2XU

Scotland 